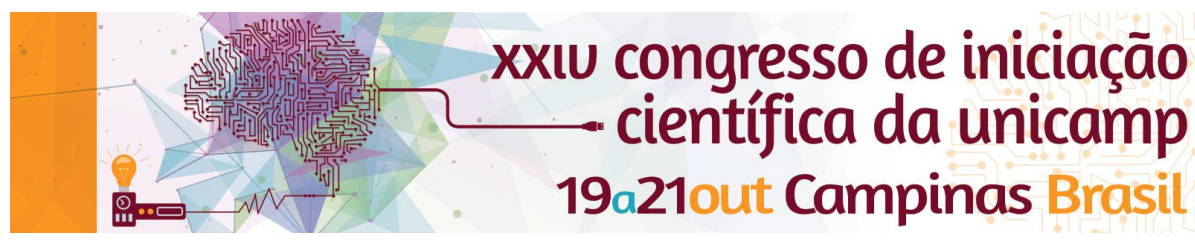

\title{
Screening of Lipases for Enantioselective Hydrolysis of 1-butiryloxyarylphosphonates.
}

\section{Leticia M. Sato*, Taisa N. Kitamura, Lucidio C. Fardelone, José Augusto R. Rodrigues e Paulo J. S. Moran.}

\section{Abstract}

The screening of lipases for use in enantioselective hydrolysis of 1-butiryloxyarylphosphonates ( \pm )-3a-b furnished the metodology for obtention of alpha-hydroxy phosphonates. These alpha-hydroxy phosphonates that can be used as building blocks for pharmaceuticals and agrochemicals compounds.

\section{Key words:}

alpha-hydroxy phosphonates, biocatalysis, enantioselective hydrolysis, lipase.

\section{Introduction}

The optically active phosphorus compounds are important classes in organic chemistry, due to their biological properties, such as enzyme inhibitors, antibiotics, antiviral agents, antitumor and agrochemicals ${ }^{1}$.

The use of lipases for resolution of racemic secondary alcohols are a great strategy in organic synthesis and in this work, we report the preliminary results for screening of enantioselective hydrolyses of 1butiryloxyarylphosphonates ( \pm )-3a-b by using Aspergillus niger AP12, Burkholderia cepacia, Burkholderia cepacia PS30, Candida antarctica, Candida cylindracea Type VII, Candida rugosa, and Pseudomonas fluorecens lipases.

\section{Results and Discussion}

The alpha-hydroxy phosphonates $( \pm)$-2a-b were synthesized using benzaldehyde, 3-chlorobenzaldehyde, respectively, 1.1 equivalent of trimethy! phosphite and oxalic acid (catalyst), without solvent, at $80^{\circ} \mathrm{C}^{2}$. The esterification reaction of alpha-hydroxy phosphonates $( \pm)$ 2a-b furnished the compounds ( \pm )-3a-b by using butyric anhydride and DMAP in dichloromethane, at room temperature, Image 1.

The preliminary results of enantioselective hydrolysis of 1butiryloxyarylphosphonates $( \pm)$-3a-b by using screening of lipases were demonstrated in Chart 1.

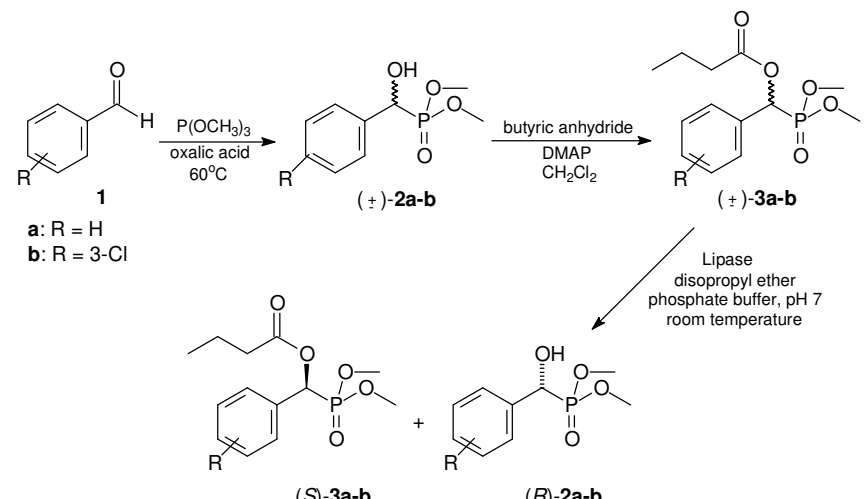

Image 1. Enantioselective hydrolysis of 1butiryloxyarylphosphonates $( \pm)$-3a-b mediated by lipases.
Chart 1. Enantioselective hydrolysis of 1butiryloxyarylphosphonates ( $( \pm)$-3a-b mediated by lipases. ${ }^{a}$

\begin{tabular}{|c|c|c|c|c|c|}
\hline Subst. & Lipase & Product & $\begin{array}{c}\text { Conv. } \\
(\%)\end{array}$ & $\begin{array}{c}\mathbf{e e} \\
(\%)\end{array}$ & $\begin{array}{c}\mathbf{E} \\
(\%)\end{array}$ \\
\hline 3a & A. niger AP12 & - & - & - & - \\
\hline 3a & B. cepacia & - & - & - & - \\
\hline 3a & B. cepacia PS30 & - & - & - & - \\
\hline 3a & C. antarctica & $\mathbf{2 a}$ & 20 & - & - \\
\hline 3a & C. cylindracea & $(\boldsymbol{R})-2 a$ & 40 & 6.0 & 1.2 \\
\hline 3a & C. rugosa & $(\boldsymbol{R})-2 a$ & 40 & 31.5 & 2.3 \\
\hline 3a & P. fluorecens & $\mathbf{2 a}$ & 40 & - & - \\
\hline 3b & A. niger AP12 & - & - & - & - \\
\hline 3b & B. cepacia & - & - & - & - \\
\hline 3b & B. cepacia PS30 & - & - & - & - \\
\hline 3b & C. antarctica & $\mathbf{2 b}$ & 20 & - & - \\
\hline 3b & C. cylindracea & $(\boldsymbol{R})-2 \mathbf{b}$ & 40 & 16.3 & 1,5 \\
\hline 3b & C. rugosa & $(\boldsymbol{R})-\mathbf{2 b}$ & 40 & 69.2 & 8.6 \\
\hline 3b & P. fluorecens & $\mathbf{2 b}$ & 40 & - & - \\
\hline
\end{tabular}

$0.6 \mathrm{mmol}$ of substrate dissolved in $3 \mathrm{~mL}$ of diisopropyl ether was added in $3 \mathrm{~mL}$ of phosphate buffer $0.1 \mathrm{M}, \mathrm{pH} 7$, containing $100 \mathrm{mg}$ of Lipase, and stirred for $12 \mathrm{~h}$ at room temperature. The products were purificated in chromatographic system Biotage using hexane/acetone gradient, and furnished isolated yields $>90 \%$. The configuration of alpha-hydroxy phosphonates was determined by comparison of the $[\alpha]_{D}{ }^{20}$ with literature ${ }^{3}\left((R)-2 \mathbf{a}[\alpha]_{D}{ }^{20}=+44.7, C 1.0 \quad \mathrm{CHCl}_{3}\right.$ and, $(R)-\mathbf{2 b}$ $\left.[\alpha]_{D}{ }^{20}=+21.5, C 2.0, \mathrm{CHCl}_{3}\right)$ and the enantiomeric excess was performed using HPLC by chiral column.

\section{Conclusions}

Enantioselective hydrolysis of 1-butiryloxyarylphosphonates ( \pm )-3a-b mediated by lipases from Candida cylindracea and Candida rugosa furnished the alpha-hydroxy alcohols in $40 \%$ of conversion, and the studies are being conducted to optimize the biocatalytic process.

\section{Acknowledgement}

The authors are grateful for financial support of this project by the FAPESP (2014/00108-9), CAPES and CNPq.

\footnotetext{
${ }^{1}$ (a) Smirnov, I.; Belogurov Jr., A.; Friboulet, A.; Masson, P.; Gabibov, A.; Renard, P.-Y, Chem.-Biol. Interact. 2013, 203, 196. (b) Sobhani, S.; Tashrifi, Z., Tetrahedron 2010, 66, 1429. (c) Grembecka, J.; Mucha, A.; Cierpicki, T.; Kafarski, P., J. Med. Chem. 2003, 46, 2641

${ }^{2}$ Vahdat, S. M.; Baharfar, R.; Tajbakhsh, M.; Heydari, A.; Bagbanian, S. M.; Khaksar, S.. Tetrahedron Lett. 2008, 49, 6501.

${ }^{3}$ Sun, L.; Guo, Q.-P.; Li, X.; Zhang, L.; Li, Y.-Y.; Da, C.-S. Asian J. Org. Chem.
} 2013, 2, 1031. 